August 15, 2013

Mr. Kevin Ramsey

Senior Project Manager

Fuel Manufacturing Branch

U.S. Nuclear Regulatory Commission

Mailstop: 3WF-13C64

11555 Rockville Pike

Rockville, MD 20852

\title{
SUBJECT: COMPARISON OF RESULTS FOR QUARTER 4 SURFACE WATER SPLIT SAMPLES COLLECTED AT THE NUCLEAR FUEL SERVICES SITE, ERWIN, TENNESSEE \\ DCN: 5198-SR-04-0
}

Dear Mr. Ramsey:

Oak Ridge Associated Universities (ORAU), under the Oak Ridge Institute for Science and Education (ORISE) contract, has completed the collection, sample analysis, and review of split surface water sample results collected at the Nuclear Fuel Services site in Erwin, Tennessee. Details of these activities are presented in the enclosed report.

Please contact me at 865.574 .0685 , or Erika Bailey at 865.576 .6659 , if you have any questions.

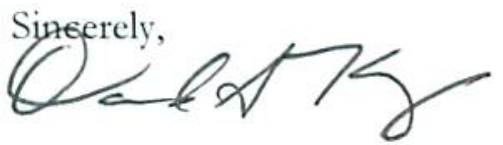

David A. King, CHP, PMP

Sr. Health Physicist/Project Manager Independent Environmental Assessment and Verification Program

DAK:fs

electronic distribution:

C. Stancil, NRC

M. Toth, NRC

C. Taylor, NRC

R. Prince, NRC

T. Vitkus, ORAU

E. Bailey, ORAU

File/5198

\begin{tabular}{|l|c|}
\hline Distribution approval and concurrence: & Initials \\
\hline Technical Review & CNBB \\
\hline Laboratory Review & WP/ \\
\hline Quality Review & \\
\hline Group Manager Review & $C N B$ \\
\hline
\end{tabular}




\section{COMPARISON OF RESULTS FOR QUARTER 4 SURFACE WATER SPLIT SAMPLES COLLECTED AT THE NUCLEAR FUEL SERVICES SITE ERWIN, TENNESSEE}

Oak Ridge Associated Universities (ORAU), under the Oak Ridge Institute for Science and Education (ORISE) contract, collected split surface water samples with Nuclear Fuel Services (NFS) representatives on June 12, 2013. Representatives from the U.S. Nuclear Regulatory Commission (NRC) and the Tennessee Department of Environment and Conservation were also in attendance. Samples were collected at four surface water stations, as required in the approved Request for Technical Assistance number 11-018. These stations included Nolichucky River upstream (NRU), Nolichucky River downstream (NRD), Martin Creek upstream (MCU), and Martin Creek downstream (MCD).

Both ORAU and NFS performed gross alpha and gross beta analyses, and Table 1 presents the comparison of results using the duplicate error ratio (DER), also known as the normalized absolute difference. A DER $\leq 3$ indicates at a 99\% confidence interval that split sample results do not differ significantly when compared to their respective one standard deviation (sigma) uncertainty (ANSI N42.22). The following equation presents the DER calculation.

$$
D E R=\frac{|P-S|}{\sqrt{U_{P}{ }^{2}+U_{S}{ }^{2}}}
$$

Where:

$\mathrm{P}=$ NFS primary sample result

$\mathrm{S}=$ ORAU $\underline{\text { split sample result }}$

$\mathrm{U}_{\mathrm{P}}=$ NFS primary sample one sigma uncertainty

$\mathrm{U}_{\mathrm{s}}=\mathrm{ORAU}$ split sample one sigma uncertainty

The NFS split sample report specifies 95\% confidence level of reported uncertainties (NFS 2013). Therefore, standard two sigma reporting values were divided by 1.96 .

In conclusion and as shown in Table 1, most DER values were less than 3 and results are consistent with low (e.g., background) concentrations. The gross beta result for sample 5198W0014 was the exception. The ORAU gross beta result of $6.30 \pm 0.65 \mathrm{pCi} / \mathrm{L}$ from location NRD is well above NFS's non-detected result of $1.56 \pm 0.59 \mathrm{pCi} / \mathrm{L}$. NFS's data package includes no detected result for 
any radionuclide at location NRD. At NRC's request, ORAU performed gamma spectroscopic analysis of sample 5198W0014 to identify analytes contributing to the relatively elevated gross beta results. This analysis identified detected amounts of naturally-occurring constituents, most notably Ac-228 from the thorium decay series, and does not suggest the presence of site-related contamination. The raw gamma spec data was transmitted to NRC via an August 12, 2013 e-mail, thus is not presented herein.

\section{REFERENCES}

ANSI N42.22. Traceability of Radioactive Sources to NIST and Associated Instrument Quality Control. American National Standards Institute.

NFS 2013. File name "June 2013 Sampling Event.pdf," e-mailed by Carol Hale/NFS to Jason Lee/ORAU on July 18, 2013. Nuclear Fuel Services. 
Table 1. Quarter 4 Results for Split Surface Water Samples Collected on June 12, 2013

\begin{tabular}{|c|c|c|c|c|c|c|c|c|c|c|c|c|}
\hline \multirow[b]{2}{*}{ Quarter } & \multirow[b]{2}{*}{ Station } & \multirow{2}{*}{$\begin{array}{l}\text { ORAU } \\
\text { Sample }\end{array}$} & \multirow{2}{*}{$\begin{array}{c}\text { NFS } \\
\text { Sample }\end{array}$} & \multirow[b]{2}{*}{ Analyte } & \multicolumn{3}{|c|}{ ORAU (pCi/L) } & \multicolumn{3}{|c|}{ NFS (pCi/L) } & \multicolumn{2}{|c|}{ DER } \\
\hline & & & & & Result & Uncert. & MDC & Result & Uncert. & MDC & Value & $\leq 3 ?$ \\
\hline \multirow[t]{2}{*}{4} & \multirow[t]{2}{*}{$\overline{N R U}$} & \multirow[t]{2}{*}{ 5198W0013 } & \multirow[t]{2}{*}{ NRU } & Gross alpha & 0.19 & 0.19 & 0.31 & 0.226 & 0.452 & 1.79 & 0.1 & YES \\
\hline & & & & Gross beta & 2.24 & 0.52 & 0.76 & 1.17 & 0.74 & 2.46 & 1.2 & YES \\
\hline \multirow[t]{2}{*}{4} & \multirow[t]{2}{*}{ NRD } & \multirow[t]{2}{*}{ 5198W0014 } & \multirow[t]{2}{*}{ NRD } & Gross alpha & 0.31 & 0.22 & 0.32 & 1.23 & 0.55 & 1.54 & 1.6 & YES \\
\hline & & & & Gross beta & 6.30 & 0.65 & 0.76 & 1.56 & 0.59 & 1.78 & 5.4 & $\mathrm{NO}$ \\
\hline \multirow[t]{2}{*}{4} & \multirow[t]{2}{*}{$\overline{\mathrm{MCU}}$} & \multirow[t]{2}{*}{ 5198W0015 } & \multirow[t]{2}{*}{$\mathrm{MCU}$} & Gross alpha & 0.35 & 0.23 & 0.32 & 0.171 & 0.398 & 1.66 & 0.4 & YES \\
\hline & & & & Gross beta & 2.06 & 0.52 & 0.76 & 1.74 & 0.67 & 2.05 & 0.4 & YES \\
\hline \multirow[t]{2}{*}{4} & \multirow[t]{2}{*}{ MCD } & \multirow[t]{2}{*}{ 5198W0016 } & \multirow[t]{2}{*}{ MCD@RR Trestle } & Gross alpha & 1.11 & 0.36 & 0.37 & 2.04 & 0.65 & 1.38 & 1.2 & YES \\
\hline & & & & Gross beta & 2.33 & 0.53 & 0.77 & 1.44 & 0.58 & 1.75 & 1.1 & YES \\
\hline
\end{tabular}

Uncert. = one sigma uncertainty; standard two sigma reporting for NFS data, thus the reported uncertainty values were divided by 1.96. $\mathrm{MDC}=$ minimum detectable concentration 